\title{
TRANSFORMAÇÕES NO MODELO INDUSTRIAL, "NOVOS" TRABALHOS E NOVA TEMPORALIDADE
}

\author{
Cássio Adriano Braz de Aquino \\ Universidade Federal do Ceará, Fortaleza, Brasil
}

RESUMO: O presente artigo visa à análise da transformação da temporalidade, como elemento chave para a compreensão das mudanças no mundo do trabalho. Tomamos como referente dessa análise as teorias dos tempos sociais e a idéia do tempo dominante na constituição dos quadros temporais das sociedades. A passagem de um modelo de temporalidade relativamente estável e quase hegemônica do modelo industrial, para um tempo cada vez mais diversificado e diluído, advindo das novas jornadas - com durações e ritmos cada vez mais complexos - não parece ser suficiente, ainda, para atribuir a perda desse domínio do trabalho na estruturação dos quadros temporais.

PALAVRAS-CHAVE: temporalidade laboral; jornadas laborais; teoria dos tempos sociais.

\section{TRANSFORMATIONS OF THE INDUSTRIAL STANDARD, "NEW" WORK AND NEW TEMPORALITY}

ABSTRACT: The present article aims to analyze transformations of temporality in the context of labor as a key element for understanding the changes in its realm. As reference for this analysis we use the theories of social time and the idea of dominant time in the constitution of the temporal frames of societies. The change from a model of relatively stable and almost hegemonic temporality of the industrial model for a more diversified and diluted time, resulting from new types of daytime jobs - controlled by more complex durations and rhythms - it still does not seem to be enough to attribute the loss of this domain of labor in constituting temporal frames.

KEYWORDS: labor temporality, daytime jobs and theories of social time.

\section{Situando a reflexão}

O presente artigo é fragmento de uma reflexão mais ampla, que visa à articulação entre novas formas de inserção laboral e a conseqüente reconfiguração do modelo de tempo a elas associado.

Como consequiência dos trabalhos desenvolvidos ao longo dos últimos três anos e que teve seu início no Curso de Doutorado, ${ }^{1}$ temos procurado investigar as mudanças da temporalidade laboral como elemento privilegiado de análise das alterações no mundo trabalho. Para que possamos compreender o recorte que resultou neste trabalho, é preciso situar o contexto de nossa reflexão. Partimos da premissa de que tempo e trabalho são elementos fundamentais e constitutivos da ordem social. A idéia de tempo social é, para nós, o alicerce que torna viável a aproximação da realidade, e que privilegia o trabalho como categoria fundamental de análise da estrutura social em constante transformação.

A superação da hegemonia do modelo industrial permite uma inquietação profunda de como podemos articular os novos modelos de inserção laboral e as novas temporalidades. O resultado dessa articulação viabiliza a contribuição de novos paradigmas para as teorias dos tempos sociais, tomando nota, nas suas formulações, do impacto que atividades sociais tão relevantes, como o trabalho, exercem.
Há um reconhecimento de que a teoria de tempos sociais é tema de estudo de inúmeros autores, com destaque para Gilles Pronovost (1996), Ramon Ramos (1992), Giovanni Gasparini (1994, 1996), Roger Sue (1995) - para citar apenas alguns. Nosso recorte, porém, vai centrar-se num diálogo crítico principalmente com os dois últimos autores, e de forma destacada com Sue (1995), para discutirmos sua idéia do surgimento de um novo domínio de temporalidade - do tempo livre - em substituição ao domínio da temporalidade laboral.

Para situar o leitor, iniciaremos com uma breve alusão ao que vem a ser a noção de tempo social. Posteriormente, nos deteremos no nosso propósito mais substantivo, qual seja, analisar os efeitos das transformações do modelo industrial na configuração da relação tempo e trabalho.

\section{O Tempo Social}

O tempo é uma categoria que está presente no campo de diversos saberes. Como afirma Gasparini (1994), é um tema de fronteira entre diversas disciplinas. Em outro texto, já o descrevíamos como um conceito complexo e em alguns casos de natureza polissêmica (Aquino, 2003).

De forma segura, poderíamos dizer que a compreensão do fenômeno da temporalidade, construída ao longo da modernidade, foi destacadamente influenciada pela filosofia e pela física. Esses territórios, no entanto, não esgotam a complexidade de abordagem do tempo. No campo 
das ciências sociais, o tempo adquire um novo estatuto, demarcado que está por recursos de compreensão histórica e sistemática, e que o tornam referência central na compreensão da ordem social. Como afirma Gasparini (1994), o tempo é uma instituição social e cultural, que ultrapassa a compreensão do tempo astronômico e físico e se insere na idéia de expressão fundamental da vida social.

É essa expressão social e cultural que dá sentido às teorias dos tempos sociais. Lembrando, ainda, Durkheim (1912/ 1992), o tempo e o espaço seriam concebidos como categorias sociais, no sentido de que não apenas derivam da sociedade, mas pelo fato de que suas expressões são sociais.

As teorias dos tempos sociais, partindo desse reconhecimento, defendem a idéia de que cada coletividade ou sociedade desenvolve referentes próprios de temporalidade, que organizam o seu funcionamento. Para tanto, estabelecem que, em cada momento histórico, há predomínio de uma atividade social que regula essa estruturação social. A idéia de um domínio de atividade social - seja através da idéia de tempo dominante (Sue, 1995) ou tempo pivô (Pronovost, 1996) - explica, de alguma forma, o modo de produção, as regras de organização e as principais atividades requeridas para essa produção.

É fundamentalmente essa idéia de dominância, ou, para sermos cautelosos, de predominância, que leva à afirmação de, que ao longo dos dois últimos séculos, vivemos de forma nítida numa 'sociedade do trabalho', uma vez que seria essa atividade social a responsável pela orientação da organização social das sociedades ocidentais contemporâneas, reconhecendo a referência temporal como mediadora dessa estruturação.

Ao longo dos últimos anos, porém, essa hegemonia temporal do trabalho passou a ser questionada, tendo por parâmetro básico desse questionamento, um discurso difundido, tantos nos meios acadêmicos como na mídia, sobre o 'fim do trabalho'. Ainda que se reconheça que falar do fim do trabalho seria algo precipitado ou até suspeitoso, uma evidência está clara: a organização laboral, que vigorou principalmente ao longo do século XX, parece perder sua hegemonia. É justamente sobre essa base, que centramos nossa reflexão. Como pensar a temporalidade laboral, diante de um quadro de profunda transformação do mundo do trabalho?

Uma análise mais profunda demandaria uma discussão sobre as duas categorias centrais de análise - tempo e trabalho, o que está presente em outros estudos já realizados ou a publicar. Contudo, parece interessante começar a refletir de forma mais criteriosa sobre uma perda de dominância do modelo industrial, como referente da expressão do mundo laboral.

Em seguida, introduziremos essa reflexão que não esgota o tema, mas apenas desafia nosso pensamento para (re)situarmos a problemática do tempo e do trabalho no contexto contemporâneo.

\section{Análise das transformações}

\section{do tempo de trabalho}

A temporalidade das sociedades ocidentais no último século, tal como foi constituída, reconhecia no trabalho e no tempo industrial seus mais significativos elementos da composição do quadro temporal. Entretanto, as transformações induzidas pelos fatores tecnológicos, econômicos, culturais e político-institucionais, ao longo das últimas décadas do século passado, tiveram repercussão direta na alteração da relação 'tempo x trabalho'. Essas transformações levaram ao surgimento de uma série de idéias sobre a perda da hegemonia do trabalho, como atividade dominante e determinante dos quadros temporais das sociedades. Contudo, parece prudente e necessária uma análise mais detida e criteriosa, antes de formular um parecer decisivo sobre a perda dessa prevalência do trabalho como atividade central de articulação do emprego do tempo, e, conseqüentemente, da idéia que guia nossas investigações, que o toma como elemento de base da constituição da ordem social.

Um dos aspectos fundamentais na concepção do trabalho, que prevaleceu ao longo do século XX, foi à concepção da sociedade salarial criada no seio do Estado de Bem-estar. A modernização da indústria, concomitante a uma forte reação por parte dos trabalhadores diante das condições de profunda exploração engendradas pelas indústrias, teve na política keynesiana um elemento decisivo para mudar a noção de trabalho que, até então, dominava o cenário sócio-laboral. As reações às extensivas horas de trabalho e às precárias condições do seu exercício, constituíram, de forma paulatina, argumentos para a abertura de negociação entre os detentores do capital e os detentores da força de trabalho, intermediados pelo Estado, que reconhecia, assim, seu caráter social, sem perder, no entanto, o foco da sua responsabilidade em impulsionar o progresso e o desenvolvimento econômico, num cenário marcado por uma crescente competição produtiva. Direitos e garantias sociais constituíram a outra face de uma relação, onde o trabalho e a remuneração financeira a ele associado, eram insuficientes como parâmetros fundamentais para dar sentido à sociedade salarial. Surge, a partir daí, a idéia do crescimento econômico e do crescimento do Estado Social concomitantes.

Dentro desse contexto, fica claro que a temporalidade, associada à idéia de jornadas, passava a constituir um elemento de reivindicação, buscando de alguma forma resgatar algo de autonomia e liberdade, para um sujeito alienado pela expropriação gerada pelo modelo típico do capitalismo industrial. Esse reconhecimento pode parecer contraditório, pois revela que o trabalho, tal como estava qualificado no modelo industrial, teria muito mais evidenciado o seu caráter instrumental e, portanto, ao ocupar uma parcela significativa do quadro temporal, tornava inviável o exercício da expressão autônoma do sujeito. 
Sendo assim, a liberação do tempo teria por objetivo a vivência de sua autonomia em outras esferas e atividades sociais. Lógico que esse pensamento não era unânime e também sobressaía a idéia da limitação física do ser humano, para reivindicar a diminuição do tempo dedicado ao trabalho.

Outro fator decisivo que exerceu influência na transformação da temporalidade industrial foi o fenômeno da expansão do consumo. O fordismo introduz a perspectiva de que os que participam da produção devem também ter a oportunidade de usufruir o crescimento produtivo (ainda que de forma restrita e, de certa forma, controlada). A intensificação do consumo também vem colaborar com esse controle e disciplina do tema, através do trabalho. Os trabalhadores, que num princípio lutavam contra a existência dos horários extensivos e impostos, começam a lutar pelo cumprimento dos horários e pela possibilidade de aumentar seu acesso ao consumo.

Um dos aspectos interessantes e que constituíram dado fundamental para a análise levada a cabo neste trabalho, é que parece ser importante reconhecer que o desenvolvimento de atividades voltadas ao consumo de bens e serviços, geradas pelo capital, prescindia de tempo, de forma que o aumento da produtividade dependia, fundamentalmente, do aumento do consumo. A idéia de que a necessidade de consumo demanda tempo proporciona uma nova (outra) relação com a temporalidade. A própria indústria necessitava, de alguma forma, produzir um novo tipo de bem para garantir o consumo de seus produtos: o tempo.

As características que marcam o domínio do tempo de trabalho podem ser compreendidas através de um duplo foco, um de corte mais quantitativo, que implica a diminuição crescente do tempo cronológico dedicado ao trabalho, mas também através de uma reconfiguração das características que estiveram vinculadas à temporalidade laboral, tais como a regularidade, a homogeneidade, o caráter mecânico e quantitativo, a linearidade, além do seu sentido abstrato e exterior.

Sue (1995) comenta que a verificação do declínio da hegemonia do tempo dominante do trabalho pode ser analisada através de uma constatação quantitativa sob uma tripla dimensão: (a) a redução da jornada laboral; (b) a redução do tempo total de trabalho com relação ao ciclo de vida; e, (c) a redução do tempo de trabalho vinculado ao que ele denomina de vida ativa.

A análise da diminuição quantitativa do tempo de trabalho é importante, porque, seguindo a lógica do mecanismo de produção de um novo tempo dominante, proposto pelo próprio Sue (1995), pouco a pouco começam a surgir outras atividades com temporalidades distintas, que terminam por se tornar autônomas, frente ao domínio da temporalidade vigente. Ao longo de todo século XX e em função das mudanças produzidas na organização produ- tiva, essas atividades foram se configurando e constituindo espaços relativamente autônomos frente à temporalidade laboral.

Segundo Husson (1998), no âmbito quantitativo, a redução da duração do trabalho advém principalmente dos ganhos e incremento da produtividade, que ele explica por meio de uma relação extremamente simplificada, mas que é tomada como uma taxa de crescimento:

\section{Emprego $=$ produção - produtividade horária - duração do trabalho}

Husson (1998), analisando o caso francês, termina por criar um modelo explicativo, que pode servir de referência para os denominados países industrializados. Reconhecendo que, ao longo do último século, a produtividade do trabalho foi multiplicada por treze, mas identificando que o crescimento do PIB não cresceu no mesmo ritmo (em torno de nove vezes, no caso francês), os dados apontam que a sociedade optou por aplicar parte do ganho da produtividade em novos mecanismos de produção, que implicaram a diminuição do volume de trabalho. Entretanto, ao analisar o aumento do emprego em $20 \%$ ao longo do século, ele conclui que a compatibilidade entre essas informações somente pode ser evidenciada com a constatação de que ocorreu uma diminuição da quantidade de horas trabalhadas. Ainda que não seja preocupação, neste artigo, uma descrição detalhada do histórico da redução das jornadas laborais, não podemos deixar de fazer a constatação desse dado concreto e de corte quantitativo, apontado por Sue (1995).

É importante analisar, contudo, que a diminuição das jornadas laborais não é um dado isolado, na perspectiva da redução do tempo de trabalho; a ela está associada também uma diminuição da chamada 'vida ativa', ou, como preferem alguns, um aumento da expectativa de vida, associado a um aumento da extensão da escolaridade e uma redução da idade de aposentadoria, características que têm sua origem na política de direitos e garantias pelo Estado de Bem-estar. Não é possível esquecer, também, que os logros obtidos não constituem um processo linear de redução do tempo de trabalho, mas se inserem numa série de lutas e conquistas sociais, que foram posteriormente transformadas em leis e formas reguladas de integrar os trabalhadores.

Nas primeiras décadas do século XX, as mudanças na esfera do trabalho estavam profundamente marcadas pelos avanços tecnológicos e transformações geradas nos processos produtivos, para atender as demandas de ganhos na produtividade. Como destaca Atalli (1985), essa verdadeira 'obsessão' da produtividade gera o aumento da amplitude do processo de produção e termina por viabilizar o desenvolvimento do setor de serviços, principalmente das atividades administrativas e de distribuição, espaço 
onde a idéia de produção em série e de economia do tempo não tinha, então, a mesma expressividade da indústria.

O crescimento do setor de serviço representa uma transformação da realidade produtiva e serve de referência, inclusive, para a precipitação das primeiras idéias do debilitamento, ou mesmo 'fim', do modelo industrial. As características mecânicas, homogêneas, quantitativas, dentre outras, que marcavam o modelo de temporalidade industrial, já não se mostravam as mais adequadas nesse novo cenário, onde os serviços adquiriam relevo e pregavam a necessidade de emergência de um novo modelo produtivo.

Se, por um lado, nas indústrias, a tecnologia tem por meta substituir uma parcela significativa do trabalho, por outro lado, os bens produzidos em determinados setores dessa mesma indústria começavam a substituir os trabalhos e serviços domésticos. Surge uma verdadeira batalha pela redução do tempo de trabalho, mas que termina por constituir um grande paradoxo, já que liberar o tempo de trabalho implica um esforço em produzir novas formas de ocupar esse tempo liberado. O tempo, mesmo não estando submetido à lógica do modelo dos primeiros momentos da industrialização, segue sendo uma obsessão permanente, ou seja, a necessidade de controlar o tempo se mantém como desafio do homem e como forma de incorporar valor à estrutura do capital.

Obter ganhos massivos de tempo nos serviços mais monótonos, substituí-los com novos objetos que se podem armazenar e utilizar-se simultaneamente, automatizar o manejo das informações, são demandas para prolongar o tempo das máquinas. Tudo isso desemboca num novo modo de pensar o tempo, de medi-lo e de datar as violências permitidas... com o fim de liberar tempo para novos objetos, o tempo acumulado é brutalmente destruído, pela inflação, as dispensas, a quebra, que são formas monetárias de sacrificios e carnavais fugazes (Attali, 1985, p. 234).

Gasparini (1996), partindo da idéia de que a formação dos quadros temporais da sociedade industrial está composta de três dimensões distintas - duração, ritmo e distribuição - em constante interação, analisa as transformações da temporalidade, a partir das alterações que se operam nessa interação. Assim, se nos momentos mais significativos do taylorismo havia uma forte tendência de atuar sobre a intensificação do ritmo com relação à própria duração, hoje em dia, Gasparini ressalta que a interação mais freqüente entre as dimensões do quadro temporal de trabalho é a permuta entre duração e distribuição no tempo de realização do trabalho, ou seja, se verifica uma tendência em reduzir o tempo externo ou de duração do tempo dedicado ao trabalho, em troca de uma flexibilização da distribuição do tempo de trabalho. A flexibilidade é o que vai definir a produtividade e, muitas vezes, chega a constituir-se a estratégia que permite e justifica a sobrevivência da organização produtiva.
A flexibilidade se constituiu, nos países mais industrializados, uma estratégia significativa utilizada pelas organizações produtivas. Ela é, sem dúvida, um dos principais elementos que caracteriza, na contemporaneidade, a vinculação tempo e trabalho. É bem verdade que a noção de 'flexibilidade' faz referência a um grande número de aplicações de termos, tais como flexibilidade tecnológica, flexibilidade jurídica, flexibilidade de remuneração, flexibilização de encargos sociais, flexibilidade de postos de trabalho, entre outras. Entretanto, a flexibilidade do tempo de trabalho está sempre vinculada, direta ou indiretamente, a essa multiplicidade de sentidos, que podem ser atribuídos à categoria flexibilidade. A flexibilidade temporal pode ser caracterizada como a capacidade de adaptação às normas e práticas relativas à organização do tempo de trabalho, frente aos obstáculos surgidos na própria organização, entre os trabalhadores ou mesmo derivada de fatos produzidos no ambiente externo.

Ao articular essas dimensões temporais com as mudanças produzidas nos âmbitos tecnológico, econômico, cultural e político-institucional, Gasparini (1996), de alguma forma, descreve fatores que influenciam os quadros temporais do trabalho e que são de extrema importância para reconhecer como a articulação ‘tempo x trabalho' constitui um elemento fundamental de análise da ordem social.

No âmbito da evolução tecnológica, o autor destaca o chamado 'labour-saving', introduzido pelas novas tecnologias. O 'labour-saving' ou 'economia de trabalho', que surge do emprego de máquinas e tecnologias de caráter quase sempre automatizadas e de alto custo, gera a necessidade de incremento da utilização dessas, como forma de garantir os custos empregados na sua aquisição (investimento). Como resultado dessa utilização mais produtiva, são criados horários atípicos dentro do padrão clássico da tradição industrial, tais como turnos à noite e fins de semana, introduzindo, com isso, a idéia de trabalho contínuo. Ainda com base no avanço tecnológico, pode ser denotado que, principalmente através da informatização e do emprego de alta intensidade de informação, a idéia de linha de montagem deixou de ser hegemônica no modelo industrial. Surge a possibilidade de romper a sincronia e dissociar tempos relativos aos processos de produção. A utilização de tal premissa, de forma mais intensiva na atividade de serviços, é um dos traços importantes da transformação do trabalho, a partir da década de 1980.

As novas relações que se estabelecem entre os países, a partir de final dos anos 1970, com a chamada 'crise do petróleo' - econômica e energética -, revelam uma reconfiguração entre a organização produtiva e o ambiente organizacional externo, gerando desafios permanentes de adaptação das empresas a uma tendência de mundialização da economia e a uma instabilidade generalizada.

Com relação ao âmbito cultural, Gasparini (1996) destaca que há uma mudança de atitude frente ao trabalho. 
Ele considera que a dualização entre tempo de trabalho e tempo livre ganha força, a tal ponto que muitos optam por um aumento do tempo livre, antes que a um aumento nos salários. Antes mesmo de prosseguir, não se pode deixar de afirmar que há, na análise de Gasparini, um problema advertido por Elias (1997), referente a uma tendência ao 'ocidente centrismo', principalmente considerando um modelo industrial do ocidente de países desenvolvidos. Não é possível imaginar uma opção dessa natureza em sociedades, ou segmentos da sociedade, onde os direitos e garantias sociais não estão 'culturalmente' estabelecidos. A idéia da sociedade salarial e do Estado de Bemestar está na base da afirmação de Gasparini. O tempo livre e sua apropriação por parte do capital poderiam constituir um trabalho a parte e prescindiria uma criteriosa análise. Ainda que não seja nosso propósito realizá-lo neste espaço, parece prudente fazer essa observação, antes de prosseguir com a explanação do pensamento do autor.

Por fim, distintas políticas levadas a cabo pelos diferentes países em termos de regulação das matérias sobre o trabalho, assim como a participação das lutas sindicais e as negociações coletivas, compõem um quadro geral, que contribui para a compreensão da relação entre trabalho e temporalidade, ao longo do século XX.

Esta análise da articulação entre as dimensões temporais, a partir dos processos de transformações produtivas, conduz a uma compreensão de que a redução quantitativa do tempo de trabalho está fortemente marcada pela adoção de políticas de flexibilização do tempo laboral. Assim, o modelo industrial, que chamaremos aqui de tradicional, dá passo a uma multiplicidade de formas de trabalhos e inserções laborais, onde os aspectos fundamentais, que caracterizaram a sociedade salarial ocidental capitalista contrato de trabalho de duração indeterminada, tempo integral, período diurno, horário fixo, semana de cinco ou seis dias - são substituídos por contratos e horários atípicos. A multiplicação das formas de articulação entre tempo e trabalho parece ser a característica mais evidente dessa nova etapa do devir social, mas é isso o suficiente para assinalar uma perda do domínio da temporalidade laboral?

Sue (1995) também se dedica a analisar a dinâmica do tempo social, que conduz ao declínio do tempo de trabalho, destacando três elementos fundamentais:

1. Mais capital, menos trabalho - apoiando seu pensamento nas idéias dos grandes 'economistas' do século XIX - Smith, Ricardo e Marx - ele analisa que, no processo de produção capitalista, o capital, produto do trabalho e de sua acumulação, tende a substituir o próprio trabalho, isto é, seja através do desemprego ou da diminuição das jornadas, se percebe a intensificação capitalista, com a redução do tempo de trabalho.

2. Da sociedade de produção à sociedade de consumo o incentivo às práticas de consumo evita a crise da su- perprodução. O desenvolvimento da sociedade industrial implica o aumento do poder de compra, mas pressupõe o concomitante aumento do tempo liberado para o consumo.

3. Tempo fora do trabalho e produtividade do trabalho - há uma crescente consideração da importância do tempo fora do trabalho para a produtividade. Se, num princípio, o tempo liberado do trabalho tinha um caráter de recuperação da força de trabalho - comum no século XIX -, passou-se à idéia de reprodução ampliada, ou seja, surgem as explicações psicológicas como justificativa para liberação do trabalho, que já não está respaldado exclusivamente pela necessidade fisiológica. Os fatores externos ao trabalho começam a adquirir relevo, implicando a defesa de uma redução considerável da sua duração.

A análise de Sue (1995), comparada a de Gasparini (1996), parece ressaltar o caráter mais social da transformação da temporalidade, principalmente por revelar uma tendência ao surgimento de outras atividades, que passam a rivalizar com o trabalho, na dominância na composição do quadro temporal. Entretanto, entre ambas há uma certa harmonia das características apontadas, pela evidência de que a tecnologia, posta a serviço do capital, pode representar mais um benefício direto à produtividade, do que ao trabalhador. Ademais, a própria exigência de incentivar o consumo gera uma necessidade de redistribuição do tempo, que não pode estar fixado de forma quase exclusiva na produção. O tempo liberado do trabalho é, pois, o novo 'mercado', para onde devem se dirigir os olhares do capital e onde devem adquirir sentido as transformações da temporalidade.

Em sua análise da mudança da temporalidade, Sue (1995) concebe que alguns elementos, que indicam o declínio do tempo de trabalho, já estavam presentes em outros momentos históricos, mas sempre impregnados da idéia de uma sociedade de abundância. Muitos teóricos, tanto da economia como da sociologia, principalmente na década de 1960, em função da rápida expansão do consumo e das aportações tecnológicas à produção, identificavam um futuro de opulência. No entanto, dois fatores devem ser considerados numa revisão dessa previsão, com base no contexto atual. Por um lado, a compreensão de que, na prática, é impossível impor um limite às necessidades humanas, e, por outro, não há como promover uma distinção explícita entre produção material e imaterial.

Sue (1995) crê que, partindo de sua teoria dos tempos sociais através de critérios objetivos que caracterizam a substituição de um tempo dominante por outro, o tempo de trabalho está assumindo uma característica cada vez mais marginal. No entanto, percebe-se que sua idéia está fixada num modelo de descrição do trabalho de corte muito industrial. Não há evidências claras de que o autor consi- 
dere a alternativa de uma ampliação do sentido e da complexidade do trabalho. Mais pertinente seria, pois, seguindo sua articulação, pensar numa marginalização do modelo de trabalho industrial tradicional, e não do trabalho num sentido mais amplo. Outra observação deve ainda ser considerada sobre a afirmação de Sue, uma vez que, em sociedades que foram majoritariamente rurais, a chegada das indústrias mais recentemente fez da submissão ao ritmo industrial - seu tempo de funcionamento - uma característica relativamente inovadora (Borsoi, 2005).

Outro aspecto denotado por Sue (1995) ratifica a perspectiva de que sua referência sobre o declínio do tempo de trabalho está baseada no modelo industrial e diretamente vinculada à lógica salarial dos países industrializados do ocidente. Ele comenta, ainda, como outra evidência da marginalização do tempo de trabalho, os efeitos dos processos de automatização, que ao princípio foi visto como um sonho a conquistar, mas posteriormente se tornou um pesadelo a ser enfrentado. O efeito dessa transformação gerada, pela automatização, é uma tendência cada vez maior de prescindir de alguns setores de mão-de-obra, o que conduziria, segundo ele, a três conseqüências diretas: concentração do emprego nas parcelas mais qualificadas da população com maior remuneração - o que Antunes (1999) classificaria como superespecialização; 'economia' de trabalho; e, por fim, regularização e diminuição dos custos do trabalho.

Sem dúvida, a discussão sobre os efeitos da tecnologia, não somente na substituição dos trabalhos mais pesados e degradantes, mas também como fator de diminuição das oportunidades de emprego, é um tema que, em si, demandaria uma análise mais aprofundada. Como exemplo de um contraponto a essa idéia, poderíamos citar o pensamento de Castells (1999), que concebe a tecnologia não como um fenômeno natural, mas como fenômeno social, não admitindo que haja uma vinculação entre o desemprego estrutural e as novas tecnologias, mas que essa relação está na dependência direta da forma como é gerida. Entretanto, o desenvolvimento tecnológico tem um impacto direto na reconfiguração laboral, e esse aspecto é o que se sobressai com relação ao nosso propósito de análise dos vínculos entre temporalidade e trabalho. A tecnologia interfere na relação espaço-temporal do trabalho, como afirma Gasparini (1996), e também força o surgimento de novas formas de trabalho, já não tão vinculadas ao modelo taylorista-fordista do princípio do século XX. As alterações operadas pela tecnologia têm repercussão na concepção de tempo vinculada ao trabalho.

Uma evidência dessa alteração está no crescimento do chamado setor quaternário, caracterizado pelos serviços pessoais. Esse tipo de serviços já não é da mesma natureza dos que levaram Bell (1972) a apontar o 'surgimento' de uma Sociedade de Serviços - plenamente justificada pelo aumento de demanda das atividades que aí se davam -, mas são tarefas e atividades que, em etapas anteriores de coesão social, eram cumpridas e desenvolvidas no âmbito privado e em função dos vínculos primários, como o parentesco. São serviços que tendem a transformar-se em trabalhos quase sempre marginais, não qualificados e que se inserem numa espécie de mercantilização das relações humanas e a conseqüente diminuição da convivência solidária.

Sem dúvida, no processo de transformação da indústria ao longo do século XX, é possível reconhecer que a lógica capitalista esteve cada vez mais centrada no capital, e menos no trabalho. Os efeitos dessa tendência de privilegiar sobremaneira ao capital estão, segundo Sue (1995), em que, se insistimos em reconhecer o tempo de trabalho como tempo dominante e elemento fundamental da ordem social, somos obrigados a aceitar que o contexto contemporâneo é o do desemprego, da precariedade laboral e do processo de exclusão massiva. Sua proposta, que é compartilhada por outros autores - De Masi (1999a, 1999b) e Dumazedier (1962/1992), que constituem uma corrente já significativa na sociologia do tempo social e lazer/ócio - é considerar o tempo de trabalho como um tempo marginal, o que daria passo à necessidade de pensar um novo registro ou principio de regulação da temporalidade, criada pela liberação crescente do tempo de trabalho e que daria origem, assim, a um possível novo tempo dominante: $\mathrm{o}$ tempo livre ou tempo liberado.

Se há uma persistência em querer resolver a crise do trabalho na sua negação, se encaminha para uma sociedade desarticulada composta de [três] 3 blocos: um primeiro composto pelos assalariados permanentes nos empregos qualificados, um segundo, de indivíduos sem emprego fixo e com estatuto precário; e, um terceiro, que evolui entre assistência social, desemprego e tarefas esporádicas. Isso representa uma sociedade onde os excluídos serão a maioria (Sue, 1995, p. 192).

Antes de prosseguir nesta linha de pensamento, parece prudente fazer algumas observações acerca dessa posição de Sue. Está claro que há evidências da diminuição da quantidade de horas trabalhadas de um modo mais genérico e considerando setores que tradicionalmente caracterizavam o mercado laboral. Nos quadros das indústrias e dos serviços públicos, de maneira geral, as lutas sindicais, associadas às transformações da organização produtiva, resultaram em uma progressiva redução da duração das horas trabalhadas. Mas o surgimento de novas formas de trabalho, além da liberalização da economia que introduziu pautas permanentes de desmantelamento das normas reguladoras do trabalho, tem pouco a pouco gerado uma nova forma de conceber o trabalho. Estaria correto afirmar sobre a perda do domínio do tempo de trabalho, se especificássemos que a referência dessa concepção de 
trabalho foi a que dominou as estruturas dos países industrializados. Hoje em dia, não reconhecer a complexificação da categoria trabalho e excluir novas formas de inserção laboral, que vão desde os serviços personalizados, até atividades precárias, típicas do mercado informal ou negro, é ter uma visão muito reduzida do fenômeno laboral.

Voltando à análise das transformações da temporalidade industrial, é importante reconhecer na desregulação do trabalho e na introdução de trabalhos a tempo parcial ou contratos por tempo determinado, uma das mais importantes evidências da diminuição do tempo de trabalho. Husson (1998) afirma que, durante a década de 1990, entre os países que compõem a Comunidade Européia, os trabalhos a tempo parcial saltaram de $10,9 \%$ para $15,5 \%$ dos ativos. Dados preliminares, publicados pelo Centro de Investigación Sociológico - CIS da Espanha, indicam que, em 2004, esse número já se aproximava dos $20 \%$. Sem dúvida, a idéia de trabalho a tempo parcial está vinculada, tanto à pressão exercida pela necessidade de flexibilizar a produção, cada vez mais dependente das flutuações externas, como pelo modelo de inserção laboral feminino, também já aludido por Antunes (1999). O trabalho em tempo parcial recobre muitas formas de vinculação laboral, como os estágios de jovens estudantes, a meia jornada, os contratos de temporada, entre outras, mas a participação no mercado laboral do contingente feminino é um dado, por si, significativo. Não pelo que representou o ingresso das mulheres no mercado de trabalho, mas pelo modelo que a ele se associou e que começa a ser generalizado.

Um dos fatores que está diretamente relacionado à noção do trabalho a tempo parcial, é que ele surge como um mecanismo de redistribuição do emprego, ou seja, a redução do tempo de trabalho e sua consequiente transformação em jornadas parciais, têm sido utilizadas como uma proposta de enfrentamento da redução da capacidade de gerar novos postos no mercado de trabalho. A perspectiva do reparto do trabalho é, portanto, outra das muitas características que surgem no seio da relação entre temporalidade e trabalho.

As mudanças ocorridas ao longo do século XX, na estrutura produtiva e na condução das políticas laborais, apontam para uma perspectiva clara de transformação da realidade do trabalho hoje - tal como estava desenhado a partir do modelo industrial e, posteriormente, com a quase hegemônica idéia de sociedade salarial. O trabalho, na sua concepção de emprego, foi referência de construção de uma sociedade relativamente homogênea. Nos países onde houve, como afirma Castel (1995), um estabelecimento significativo da sociedade salarial, a condição dos assalariados funcionava como princípio de diferenciação das chamadas populações periféricas, que constituíam os bolsões de pobreza, pouco efetivos e organizados para questionarem o modelo social. O modelo salarial servia de refe- rência a uma identidade social. A idéia de uma referência constitutiva da identidade, que é designada pelo trabalho, também sofre um novo descentramento, quando ocorre uma transformação dos parâmetros de construção, não apenas do quadro temporal, que teve no trabalho de jornada completa e estável sua referência, mas também na própria vivência de uma nova forma de temporalidade, caracterizada pela experimentação de um tempo calcado em múltiplas coexistências e na velocidade. O impacto dessa transformação na subjetividade do sujeito trabalhador é um ponto importante a ser estudado, uma vez que remete à exigência de constituir um novo perfil de trabalhador, tomado como sujeito da reestruturação do trabalho.

O estudo das novas formas de vinculo entre tempo e trabalho viabiliza e adquire o perfil de um elemento a mais no estudo da contemporaneidade laboral. Nas três últimas décadas, as decisões estratégicas, tomadas por países industriais do ocidente, privilegiam as novas políticas de organização produtiva, em detrimento de políticas sociais, levando a um debilitamento progressivo do conjunto das políticas keynesianas, que marcaram o Estado de Bemestar. Reconhecidamente, o liberalismo crescente das práticas econômicas promoveu uma remercantilização das relações sociais e atuou de forma decisiva sobre as esferas das relações laborais e da prática social. Neste novo cenário, que está ainda em processo de construção, é difícil precisar os efeitos em longo prazo. Há, contudo, duas evidências diretamente vinculadas ao trabalho, já perfeitamente identificáveis: um aumento considerável do desemprego, numa perspectiva estrutural, e uma considerável precarização laboral.

A temporalidade constitui um fator preponderante para revelar essas evidências. Daí o empenho em aprofundarmos seu papel no estudo do mundo do trabalho. Os novos modos de inserção laboral estão pautadas por regras de tempo cada vez mais distintas do que dominou a chamada sociedade industrial. Por isso, há a necessidade de investigar o que significa para o trabalhador aspectos que marcam a precarização laboral e que trazem no tempo o substantivo da sua realidade - jornadas parciais, contratos por tempo definido e reparto do trabalho.

\section{Notas}

Tiempo y trabajo: un análisis de la temporalidad laboral en el sector de ocio-hostelería y turismo - y sus efectos en la composición de los cuadros temporales de los trabajadores. Tese defendida no Departamento de Psicología Social da Universidad Complutense de Madrid em junho de 2003 sob a orientação do Prof. Dr. José Luis Álvaro.

\section{Referências}

Antunes, R. (1999). Os sentidos do trabalho: Ensaio sobre a afirmação e a negação do trabalho. São Paulo, SP: Boitempo. 
Aquino, C.A.B. "Transformações no modelo industrial, 'novos' trabalhos e nova temporalidade"

Aquino, C. (2003) Tiempo y trabajo: un análisis de la temporalidad laboral en el sector de ocio-hostelería y turismo-y sus efectos en la composición de los cuadros temporales de los trabajadores. Tese de Doutorado não-publicada, Programa de Doutorado em Psicologia Social, Departamento de Psicología Social de la Universidad Complutense de Madrid, Espanha.

Attali, J. (1985). Historias del tiempo. México: Fondo de Cultura Económica.

Bell, D. ( 1972 ). El advenimiento de la sociedad post-industrial. Madrid, España: Alianza.

Borsoi, I. (2005) O modo de vida dos novos operários: Quando purgatório se torna paraíso. Fortaleza, CE: Editora da Universidade Federal do Ceará.

Castel, R. (1995). Las metamorfosis de la cuestión social: una crónica del salariado. Barcelona, España: Paidós.

Castells, M. (1999) La era de la información: economía, sociedad y cultura: Vol. 1. La sociedad en red. Madrid, España: Alianza.

De Masi, D. (1999a). A sociedade pós-industrial. São Paulo, SP: SENAC.

De Masi, D. (1999b). Desenvolvimento sem trabalho. São Paulo, SP: Esfera.

Dumazedier, J. (1992). Vers une civilisation du loisir? Paris: Èditions du seuil. (Original publicado em 1962)

Durkheim, E. (1992). Las formas elementales de la vida religiosa: el sistema totémico en Australia. Madrid, España: Akal D.L. (Original publicado em 1912)

Elias, N. (1997). Sobre el tiempo. México: Fondo de Cultura Económica.

Gasparini, G. (1994). La dimensione sociale del tiempo. Milão, Itália: Angeli.
Gasparini, G. (1996). Tempo e trabalho no ocidente. In J-F Chanlat. O indivíduo nas organizações: Vol. 3. Dimensões esquecidas (pp. 111-126). São Paulo, SP: Atlas.

Husson, M. (1998). Le temps de travail. In J. Kergoat, J. Boutet, H. Jacot \& D. Linhart (Eds.), Le monde du travail. (pp. 180-188). Paris: Èditions la découverte.

Pronovost, G. (1996). Sociologie du temps. Bruxelles, Belgium: De Boek Université.

Ramos, R. (1992) Tiempo y sociedad. Madrid, España: Centro de Investigaciones Sociológicas

Sue, R. (1995). Temps et ordre social. Paris: PUF.

Cássio Adriano Braz de Aquino é Professor Adjunto do Departamento de Psicologia da Universidade Federal do Ceará (UFC). Doutor em Psicologia Social pela Universidad Complutense de Madrid. Organizador do livro Psicologia Social: desdobramentos e aplicações.

braz.aquino@uol.com.br

\section{Transformações no modelo industrial,} "novos" trabalhos e nova temporalidade

Cássio Adriano Braz de Aquino

Recebido: 04/07/2006

$1^{\mathrm{a}}$ revisão: 08/11/2006

Aceite final: 25/12/2006 